Check for updates

Cite this: RSC Adv., 2021, 11, 16557

Received 12th March 2021

Accepted 27th April 2021

DOI: $10.1039 / \mathrm{d} 1 \mathrm{ra01987b}$

rsc.li/rsc-advances

\section{Recent progress of conductive 3D-printed electrodes based upon polymers/carbon nanomaterials using a fused deposition modelling (FDM) method as emerging electrochemical sensing devices}

\author{
Muhamad Huzaifah Omar, ${ }^{a}$ Khairunisak Abdul Razak, ${ }^{\text {bc }}$ Mohd Nadhir Ab Wahab ${ }^{\mathrm{d}}$ \\ and Hairul Hisham Hamzah (D)*a
}

3D-printing or additive manufacturing is presently an emerging technology in the fourth industrial revolution that promises to reshape traditional manufacturing processes. The electrochemistry field can undoubtedly take advantage of this technology to fabricate electrodes to create a new generation of electrode sensor devices that could replace conventionally manufactured electrodes; glassy carbon, screen-printed carbon and carbon composite electrodes. In the electrochemistry research area, studies to date show that there is a demand for electrically 3D printable conductive polymer/carbon nanomaterial filaments where these materials can be printed out through an extrusion process based upon the fused deposition modelling (FDM) method. FDM could be used to manufacture novel electrochemical 3D printed electrode sensing devices for electrochemical sensor and biosensor applications. This is due to the FDM method being the most affordable 3D printing technique since conductive and non-conductive thermoplastic filaments are commercially available. Therefore, in this minireview, we focus on only the most outstanding studies that have been published since 2018 . We believe this to be a highly-valuable research area to the scientific community, both in academia and

${ }^{a}$ School of Chemical Sciences, Universiti Sains Malaysia (USM), 11800, Gelugor, Penang, Malaysia.E-mail: hishamhamzah@usm.my

${ }^{b}$ Nanobiotechnology Research and Innovation (NanoBRI), Institute for Research in Molecular Medicine (INFORMM), Universiti Sains Malaysia, 11800, Gelugor, Penang, Malaysia

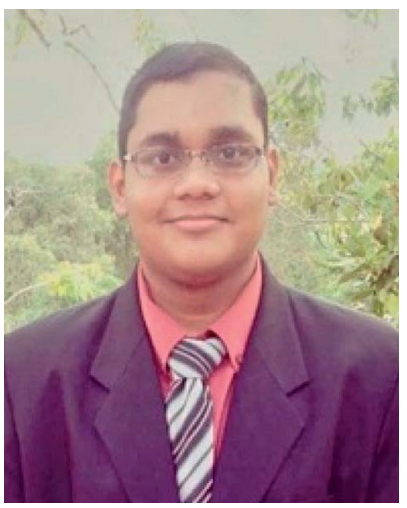
developing electrochemical biosensors.
Huzaifah Omar received his first degree in Chemistry with firstclass honours in 2020 from the Universiti Sains Malaysia (USM). He is currently pursuing his master research degree under the supervision of $\mathrm{Dr}$ Hairul Hisham Hamzah to work on the fabrication and characterisation of the 3D-printed electrodes from $3 D$ printable conductive polymer/carbon nanomaterial filaments for
'School of Materials and Mineral Resources Engineering, Engineering Campus, Universiti Sains Malaysia, 14300, Nibong Tebal, Penang, Malaysia ${ }^{d}$ School of Computer Sciences, Universiti Sains Malaysia, 11800, Gelugor, Penang, Malaysia

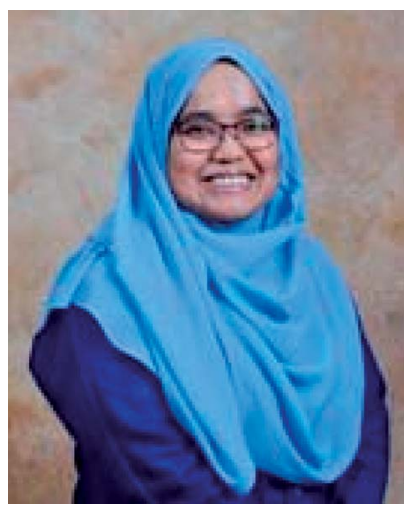

Professor Khairunisak Abdul Razak is currently a professor at the School of Materials and Mineral Resources Engineering, USM. She obtained her bachelor degree from the Universiti Kebangsaan Malaysia (UKM) in 1999. In 2007, she received her $\mathrm{PhD}$ degree in chemical and materials engineering from the University of Auckland, New Zealand. She was appointed as senior lecturer in 2008, associate professor in 2011 and professor in 2017. She was trained in Nanobiotix SA, Paris in 2008 in the field of nanobiotechnology. Her research interest is on sensors, biosensors, electronic ceramic, and nanomaterials for electronic and biomedical applications. 
industry, to enable novel ideas, materials, designs and methods relating to electroanalytical sensing devices to be generated. This approach has the potential to create a new generation of electrochemical sensing devices based upon additive manufacturing. This minireview also provides insight into how the research community could improve the electrochemical performance of 3D-printed electrodes to significantly increase the sensitivity of the 3D-printed electrodes as electrode sensing devices.

\section{Introduction}

Three-dimensional (3D) printing technology in the electrochemistry research field is a technological advancement from additive manufacturing. The researchers have illustrated many novel electrochemistry applications such as fabricating electrochemical sensor ${ }^{1}$ and electrochemical biosensor ${ }^{2}$ electrodes, producing energy storage devices, ${ }^{3}$ and building chemical reactors ${ }^{4}$ and microfluidic devices. ${ }^{5}$ To date, $3 \mathrm{D}$ printing technology has gained popularity among electrochemists to print 3D electrochemical objects. Several advantages compared to traditional manufacturing methods include it being rapid and low cost and eco-friendly, and there being various printing materials that can be used for manufacturing products and that can be printed in multiple shapes and complex geometries. There are numerous types of 3D printing processes, including binder jetting, materials extrusion, materials jetting, powder bed fusion, sheet lamination, photopolymerisation and directed energy deposition. ${ }^{6,7}$

The most common 3D product used for fundamental and applications electrochemistry is a 3D-printed electrode based upon 3D printable conductive polymers-based carbon nanomaterials. For instance, polymer materials containing carbon nanomaterials such as graphene, carbon black (CB) and carbon nanotubes (CNTs) will exist in thermoplastic filament form. This will be discussed in detail in the next section. Essentially, to print 3D-printed electrodes using those filament materials, a fused deposition modelling (FDM) method based on the extrusion process $^{\mathbf{8 , 9}}$ is used in various $3 \mathrm{D}$-printed electrodes with different design and geometrical shapes. Using the FDM technique, continuous layers will be deposited by the extruded polymer filament and finally formed the 3D printed electrode products. This method has been discussed in detail in a minireview by Patel and co-workers. ${ }^{1}$ In their review, the advantages of using the FDM 3D printing method in the fabrication of 3D-printed electrodes from 3D printable conductive polymer/ nanomaterial filaments for electrochemical sensors were discussed. However, in this minireview, we will only focus on the recent progress of the fabricated 3D-printed electrodes using the composite $3 \mathrm{D}$ printable conductive carbon nanomaterials with polymers for electrochemical sensors and biosensors.

\section{D printable conductive polymer/ carbon nanomaterial filaments for fabricating 3D-printed electrodes}

Recent studies showed that carbon nanomaterials reinforced with polymeric filaments as feedstocks for the FDM 3D printing method are popular among researchers in 3D printing applications. Graphene, CB, and CNTs are common carbon nanomaterials used as conductive filler materials in past studies. ${ }^{\mathbf{1 0 - 1 4}}$ The conductive filaments either can be commercially purchased, or can be made in house for further investigations. These materials have obtained high interest among the researchers because of their outstanding properties in making 3D-printed electrodes. For example, graphene has high thermal conductivity and low resistivity, ${ }^{13}$ while $\mathrm{CB}$ has higher conductivity, high surface area and stability. ${ }^{\mathbf{1 5}}$ Besides, CNTs can accommodate nucleation sites to bind with the reinforcing

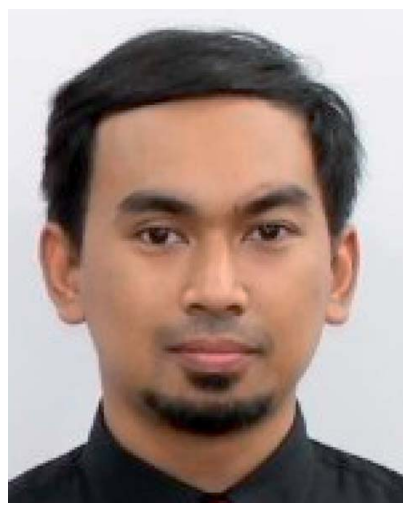

Mohd Nadhir Ab Wahab is a senior lecturer at the School of Computer Sciences, Universiti Sains Malaysia (USM). He received his B.Eng. (Hons.) Mechatronics Engineering in 2010 and M.Sc. Mechatronics Engineering in 2012 from the Universiti Malaysia Perlis (UNIMAP). Afterwards, he received his $P h D$ degree in Robotics and Automation System in 2017 from the University of Salford, UK. His main research interests are mobile robotics, artificial intelligence, computer vision, optimization, navigation, and path planning.

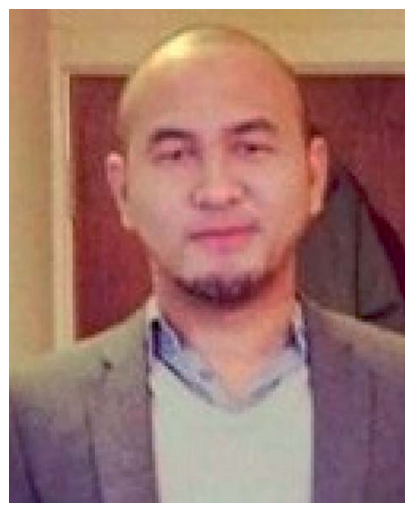

Hairul Hisham Hamzah received his bachelor and master research degrees in 2006 and 2010, respectively, from the Universiti Putra Malaysia (UPM). In 2013, he then pursued his $P h D$ research at the University of Southampton, UK, under the supervision of Professor Philip N. Bartlett. In April 2017, he had successfully defended his PhD thesis. Then, in May 2017, he moved to the University of Brighton, UK, to take up a position as a postdoctoral research assistant in Professor Bhavik Patel's lab at the School of Pharmacy and Biomolecular Sciences. Currently, he has been a senior lecturer at the School of Chemical Sciences, Universiti Sains Malaysia (USM) since January 2018. 
polymer matrix easily. ${ }^{13}$ Various types of polymer materials such as polylactic acid (PLA), ${ }^{16}$ acrylonitrile butadiene styrene (ABS), ${ }^{17}$ polyimide (PI) ${ }^{18}$ and polyurethane ${ }^{14}$ have been reinforced with these carbon nanomaterials as $3 \mathrm{D}$ printable conductive thermoplastic filaments.

The standard commercially available $3 \mathrm{D}$ printable conductive thermoplastic filaments used in printing 3D-printed electrodes used are PLA/graphene, PLA/CB, PLA/CNTs, and ABS/CB. Nevertheless, the primary key aspect that needs consideration before printing the 3D-printed electrodes using thermoplastic 3D printable conductive nanomaterials is percolating structure carbon nanomaterial fillers within the polymer matrix. This factor will influence the flow performance of the printed electrodes, by impeding the current through the non-conductive polymers. This is called the threshold limit, or percolation threshold, governing the electrical conductivity of 3D printable conductive polymers/nanomaterials by their electrical percolation. They require a minimum nanofiller content, where this scientifically refers to volume fraction to convert insulators (polymers) into conductive composite nanomaterial filaments. The minimum volume fraction of carbon nanofillers essentially depends on several factors such as the shape and size distribution of the carbon nanofillers in the polymer matrix, attractive interactions between the polymers and carbon nanofillers in the filament form, and processing methods (dispersion and agglomeration of carbon nanomaterials into the polymer). ${ }^{19}$ As discussed by Banks et al., ${ }^{16}$ a commercially available PLA/ graphene $3 \mathrm{D}$ filament only contains $8 \%$ of graphene. This is considered a very low active nanofillers that could limit the electrochemical performance of the printed electrodes as reflected by a shallow percolation threshold, giving a poor electrical percolation after the printing process.

One interesting study on the development of 3D printable thermoplastic filament based-polyimide (TPI) with different CNT contents to investigate its thermal and electrical properties was reported by $\mathrm{Wu}$ and co-workers. ${ }^{18}$ Their work studied the tensile and bending properties of pure TPI 3D printing specimens printed by the nozzles with different diameters that could replace aerospace metal and structural parts. They varied the contents of CNTs as $1 \% \mathrm{wt}, 3 \% \mathrm{wt}, 5 \% \mathrm{wt}, 7 \% \mathrm{wt}$ and $9 \% \mathrm{wt}$ in the TPI matrix as illustrated in Fig. 1A. Using an insulation resistance tester, they found that the conductive resistivity of the TPI/CNTs filament decreases gradually with the increase of the filling ratio of CNTs in the TPI resin matrix, as shown in Fig. 1B. From the conductive resistivity plot, the conductive percolation threshold for the TPI/CNTs 3D filament was found to be $3 \%$ wt of CNTs.

In a different study by Bank et al., ${ }^{16}$ utilising a PLA polymer as an insulator matrix with varying contents of nanographite (NG) to make conductive 3D printable NG-PLA filaments with different fillings of NG, containing 1, 5, 15, 20, 25, 30 and $40 \%$ wt were developed and tested towards their printability to make the 3D-printed electrodes. Then, the physicochemical electrochemical properties of the developed filaments and 3Dprinted electrodes were evaluated. The study has found that the loaded NG powder of $20 \%$ wt in the PLA exhibits a sufficient percolation over the measured resistivity $\left(\Omega \mathrm{cm}^{-1}\right)$ as depicted in Fig. 1C. The authors concluded that PLA/NG filament at
A
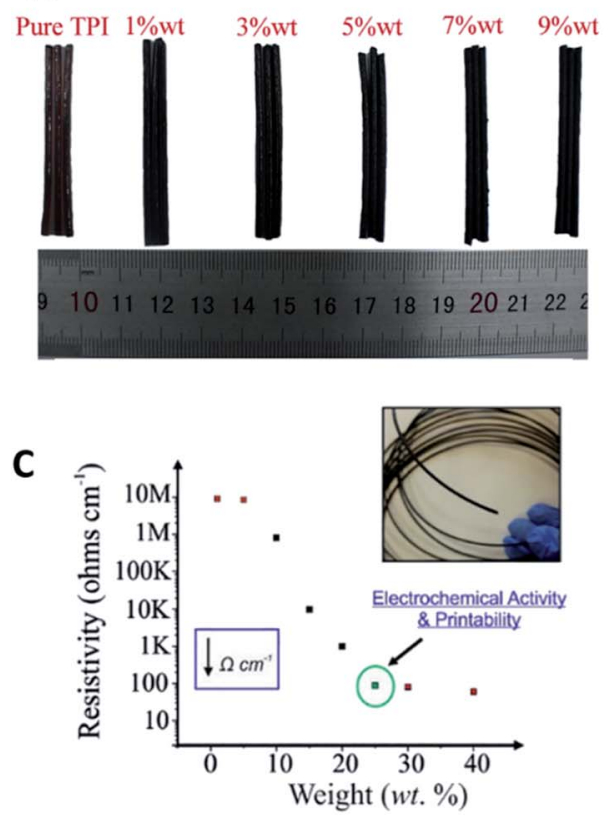

B
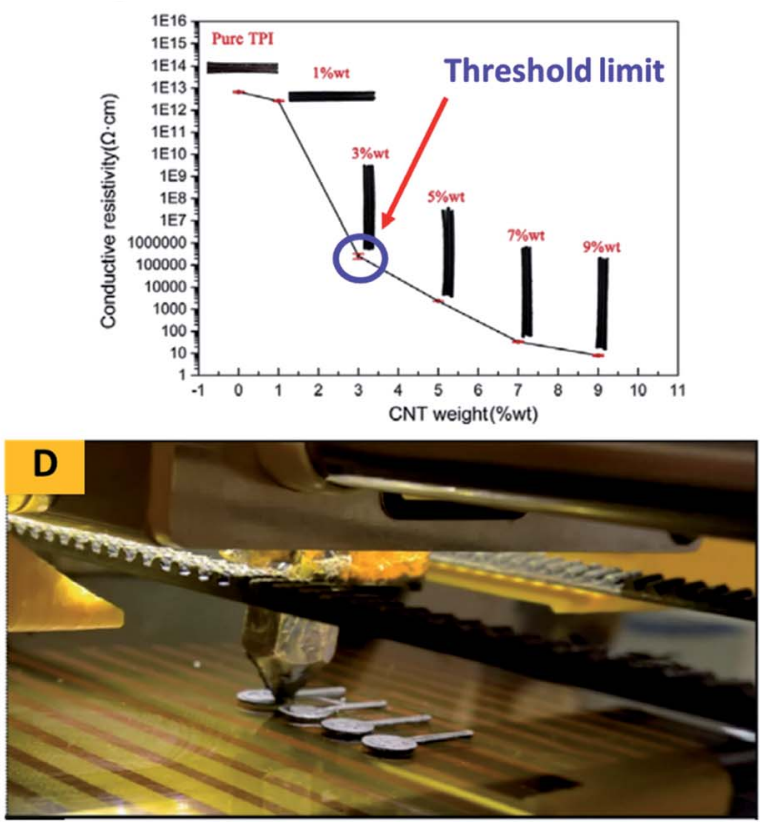

Fig. 1 (A) The developed conductive TPI/CNTs 3D printable filaments with varying percentages of CNTs; $1 \%$ wt, 3\% wt, 5\% wt, 7\% wt and 9\% wt. (B) Conductive resistivity of TPI/CNTs 3D printable filaments; pure PI and a variety of loaded CNTs; $1 \%$ wt, 3\% wt, 5\% wt, 7\% wt and 9\% wt. (C) Conductive resistivity of the developed PLA/NG 3D printable filaments, filled with a variety of loaded NG; $1 \%$ wt, $5 \%$ wt, $15 \%$ wt, $20 \%$ wt, $25 \%$ wt, $30 \%$ wt and 40\% wt. (D) FDM 3D printing process to print PLA/NG 3D-printed electrodes, utilised for electrochemical characterisation. This figure has been reproduced from ref. 16 and 18 with permission from ELSEVIER, copyright 2019 and 2020, respectively. 
$20 \%$ wt gave a superior conductivity. Thus at $25 \%$ of the loaded PLA/NG could be a threshold limit for their developed 3D filament as above $25 \%$ wt of NG may impede electrical conductivity of conductive 3D filament by the PLA matrix.

Additionally, the developed 3D filaments are difficult to be printed out using FDM 3D-printer, because the filaments are too brittle due to the lack of the PLA contents that decreased the attractive interaction between the PLA-NG filament. It is interesting to note that the fabricated 3D-printed electrodes in their study (Fig. 1D) were printed from a filament, comprised of $75 \%$ PLA and 25\% NG, and were applied for the simultaneous detection of lead(II) and cadmium(II) ions. Therefore, they suggested that the volume fraction obtains the best anisotropic conductivity of their 3D printed electrodes, comprising $25 \%$ of NG and $75 \%$ of PLA. This study has shown a significant improvement in the volume fraction form of the commercially available 3D printable polymer/graphene filaments, where the highest filling of graphene in PLA is only $8 \% .^{\mathbf{1 6}}$

\section{Effect of printing orientations, chemical treatments, and thermal treatments for electrochemical enhancement of polymer/carbon nanomaterial 3D-printed electrodes}

Studies to date show that many articles reported on the activation of the 3D-printed electrodes to enhance the electrodes' electrochemical performances since the as-printed electrodes exhibit insufficient electrochemical activity in their native state. However, recently, Patel et al. ${ }^{20}$ have printed PLA/CB 3D-printed electrodes with different layers of thicknesses; 0.1, 0.2, 0.3 and $0.4 \mathrm{~mm}$, and different printing orientations (vertical and horizontal) as shown in Fig. 2. The main interest of their study was to investigate the effects of different printing layer thickness and orientation on resistivity, and heterogeneous electron transfer rate from the PLA/CB 3D-printed electrodes.

The electrochemical behaviours of the $3 \mathrm{D}$ printed electrodes were carried out by using $1 \mathrm{mM}$ of ruthenium hexamine(III) chloride in $0.1 \mathrm{mM}$ potassium chloride $(\mathrm{KCl})$ and $1 \mathrm{mM}$ serotonin (5-HT) in Krebs' buffer solution ( $\mathrm{pH} 7$ ) for cyclic voltammetry $(\mathrm{CV})$ and ferricyanide/ferrocyanide mixture in $1 \mathrm{M} \mathrm{KCl}$ for electrochemical impedance spectroscopy (EIS). From the result obtained, thinner PLA/CB 3D-printed electrodes that are printed in vertical orientation have facilitated faster electron transfer reactions and have lowered charge-transfer resistance $\left(R_{\mathrm{ct}}\right)$ compared to thicker PLA/CB 3D-printed electrodes printed in the horizontal direction. They conclude that the low layer of thickness printed in the vertical printing orientation gave the best electrochemical behaviour to PLA/CB 3D-printed electrodes. The authors advocate that printing in a vertical printed direction gives a lower air voids effect, resulting in lower resistance between filaments during the printing process. The authors also imply that printing in the vertical orientation method is more compact, and ordered PLA/CB structures, than the horizontal printing orientation as the density of CB particles

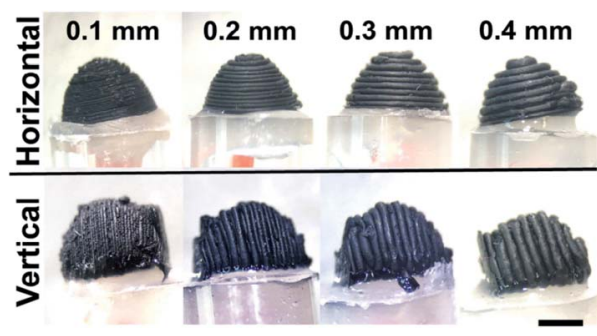

Fig. 2 Different printing orientations of PLA/CB 3D-printed cone electrodes with different printing thicknesses; $0.1 \mathrm{~mm}, 0.2 \mathrm{~mm}$, $0.3 \mathrm{~mm}$ and $0.4 \mathrm{~mm}$. The PLA/CB 3D-printed electrodes used for electrochemical characterisation. This figure has been retrieved from ref. 20 with permission from ELSEVIER, copyright 2020.

is higher than PLA making CB more oriented to the centre, while PLA pushed to the side. This makes the vertical orientation printing method that prints in parallel and side to side, has more advantage than the horizontal orientation printing method.

As mentioned previously, the 3D-printed electrode surfaces can be chemically activated to enhance the electrochemical activity of the 3D-printed electrodes based-polymer/carbon nanomaterial filaments. To the best of our knowledge, Pumera and co-workers ${ }^{21}$ have been the first group that established a simple activation approach of the PLA/graphene 3Dprinted electrodes surfaces with solvent and electrochemical activations. The solvent activation was activated in dimethylformamide (DMF). In contrast, the electrochemical activations were conducted by applying a constant potential at 1.5, 2.0 and $2.5 \mathrm{~V}$ vs. $\mathrm{Ag} / \mathrm{AgCl}$, using a phosphate buffer solution of $\mathrm{pH}$ 7.2 , performed at different times from 0 to $250 \mathrm{~s}$ via chronoamperometric technique. The activated PLA/graphene 3Dprinted electrodes were then investigated in $\left[\mathrm{Fe}\left(\mathrm{CN}_{6}\right)^{-4 /-3}\right]$ redox probe after the activation steps. The electrochemical performances of the untreated and treated electrodes were accessed toward the $\left[\mathrm{Fe}\left(\mathrm{CN}_{6}\right)^{-4 /-3}\right]$ ions by comparing the heterogeneous rate constant electron $\left(k_{\mathrm{o}}, \mathrm{cm} \mathrm{s}^{-1}\right)$, calculated using the Nicholson method. Interestingly, they found that the $k_{\mathrm{o}}$ significantly increased from $2.13 \times 10^{-5} \mathrm{~cm} \mathrm{~s}^{-1}$ (activated in $\mathrm{DMF}, 10 \mathrm{~min}$ ) to $2.43 \times 10^{-3} \mathrm{~cm} \mathrm{~s}^{-1}$ (activated electrochemically at $150 \mathrm{~s})$.

Another intriguing report from Pumera et $a .^{22}$ is using different solvents to activate the PLA/graphene 3D-printed electrodes, demonstrating the effect of polar protic and polar aprotic solvents used to activate electrodes (Fig. 3A) by monitoring the $k_{\mathrm{o}}$ and electrochemical double-layer capacitance. Polar protic solvents consist of deionized water, methanol and ethanol, whilst polar aprotic solvents consist of acetone and DMF tested on the PLA/graphene 3D-printed electrodes during the solvent activation steps. The electrochemical behaviour of the electrodes was investigated in $1 \mathrm{mM}\left[\mathrm{Fe}\left(\mathrm{CN}_{6}\right)^{-4 /-3}\right]$ solution in $0.1 \mathrm{M} \mathrm{KCl}$, while the capacitance behaviour was tested in 1.0 M sodium hydroxide $(\mathrm{NaOH})$. From the results obtained, the solvent-activated PLA/graphene 3D-printed electrodes increased the electroactive surface area of the electrodes. However, polar aprotic solvents (DMF and acetone) have had a major effect on 
A

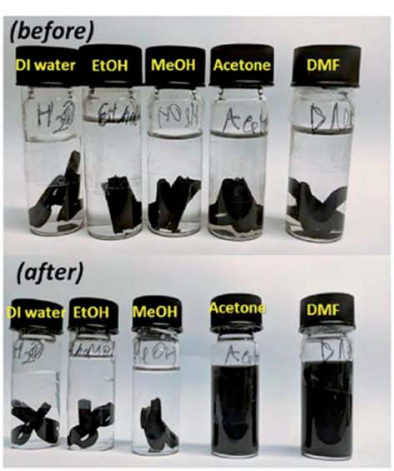

B

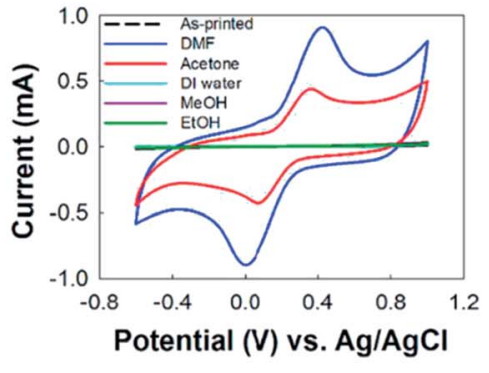

C

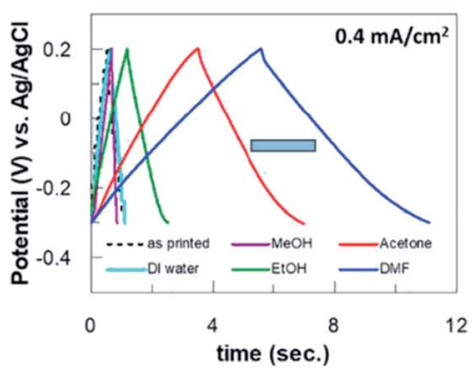

Fig. 3 (A) Chemical solvent treatment for PLA/graphene 3D-printed electrodes in the vials with various solvents before, and after activation steps. The solvents used were DI water, ethanol, methanol, acetone and DMF. (B) CV responses for the activated PLA/graphene 3D-printed electrodes, treated in ethanol, methanol, DI water, acetone and DMF, respectively. (C) Galvanostatic charge-discharge responses from PLA/ graphene 3D-printed electrodes in $1.0 \mathrm{M} \mathrm{NaOH}$, activated in different solvents at a constant current of $0.4 \mathrm{~mA} \mathrm{~cm}{ }^{-2}$. This figure been reproduced from ref. 22 with permission from ELSEVIER, copyright 2019.

the activated PLA/graphene 3D-printed electrodes and showed higher currents in $\mathrm{CV}$ peaks for $\left[\mathrm{Fe}\left(\mathrm{CN}_{6}\right)^{-4 /-3}\right]$ when compared to the polar protic solvents, as shown in Fig. 3B. However, they concluded that the obtained $k_{\mathrm{o}} v i a$ acetone activation is higher than that of the $k_{\mathrm{o}}$, activated in DMF since the activation of 3Dprinted electrodes in acetone made the electrode surface rougher, than the inactivated 3D-printed electrodes in DMF.

Meanwhile, all the electrodes showed pseudo-capacitor behaviour in the capacitance. The areal capacitance produced by the solvent-activated PLA/graphene 3D-printed electrodes were higher than the unactivated 3D-printed electrodes. However, polar aprotic solvents-activated electrodes have superior areal capacitance, compared to polar protic solventsactivated electrodes, as shown by galvanostatic chargedischarge responses in Fig. 3C. Overall, the activated PLA/ graphene 3D-printed electrode in DMF provides the best supercapacitor performance compared to other solvents. Nevertheless, the authors have recommended using acetone rather than DMF as an activation, as it is less dangerous, and still gives an excellent activation solvent to be used in the pretreatment of 3D-printed electrodes.

A different approach, reported by Vaněčková et al. ${ }^{23}$ discussed PLA/CB 3D-printed electrodes' electrochemical behaviours. The PLA/CB 3D-printed electrodes fabricated by the FDM method and a controlled electrode made from the cut filament were also prepared. Then, the faradaic peak currents, generated from the CVs were compared with theoretical values in order to investigate the relative effective surface area of electrodes. Nevertheless, before the 3D-printed electrode used, the electrodes were activated using a $0.3 \mathrm{M}$ sodium sulphate $\left(\mathrm{Na}_{2} \mathrm{SO}_{4}\right)$ as an anode terminal, whereas a thin gold electrode was a cathode terminal in a U-cell. Then, a constant voltage was applied with the range $0-25 \mathrm{~V}$ between the two electrodes, where time was set from 0 to $60 \mathrm{~s}$ to monitor the electric current. After the electrochemical treatment, the electrode's electrochemical behaviours were studied in $5 \times 10^{-4} \mathrm{M}$ ruthenium(III) acetylacetonate $\left(\mathrm{Ru}(\mathrm{acac})_{3}\right)$ in $0.3 \mathrm{M} \mathrm{Na}_{2} \mathrm{SO}_{4}$ using the $\mathrm{CV}$ technique. Both electrodes showed a faradaic response parallel to platinum (Pt) and GC electrodes. The anodic and cathodic potential peak separation $\left(\Delta E_{\mathrm{p}}\right)$ values for both electrodes obtained was between 80 to $85 \mathrm{mV}$. These values are higher than the theoretical value of $\Delta E_{\mathrm{p}}$, which is $57 \mathrm{mV}$ for reversible transfer of one electron reaction. This indicates that the electrode kinetics for the 3D-printed and cut filament electrodes is lower than expected. However, according to the authors, the $\Delta E_{\mathrm{p}}$, values obtained are higher than the literature values based on past research using PLA composites which range between 100 to $410 \mathrm{mV}$. The authors also showed that the 3D-printed and cut filament electrodes have a similar electroactive surface area which means that the electroactive area sites are not altered by the FDM printing method. Thus, the authors suggest that the electron transfer characteristics of the PLA/CB 3D-printed electrode are similar, and comparable to the conventional metallic and carbon electrodes.

Bonacin et $a l .{ }^{24}$ reported an interesting report where they investigated different approaches in treating the PLA/graphene nanoribbon 3D-printed electrodes before the use of the 3Dprinted electrodes in dopamine detection. The techniques involved electrochemical activation, mechanical polishing using alumina suspension and chemical solvents. The authors treated the 3D-printed electrodes using chronoamperometric technique in the electrochemical activation by applying a constant potential at $+1.8 \mathrm{~V} v s$. SCE for $900 \mathrm{~s}$ in a phosphate buffer solution, $\mathrm{pH}$ 7.4. They then used $\mathrm{CV}$, scanned from $0 \mathrm{~V}$ to $-1.8 \mathrm{~V}$ vs. SCE at a scan rate of $50 \mathrm{mV} \mathrm{s}^{-1}$. In contrast, for mechanical polishing, the 3D-printed electrodes were polished with $0.3 \mu \mathrm{M}$ alumina suspension in a polishing pad, polished in a figure-8 pattern. The polishing durations were varied in 1,0 , $3,0,5,0$ and $10 \mathrm{~min}$.

Meanwhile, for chemical solvent activations, four different solvents were employed; DMF, $1 \mathrm{M} \mathrm{NaOH}, 7.9 \mathrm{mM} \mathrm{HNO}_{3}$ and $0.5 \mathrm{M} \mathrm{H}_{2} \mathrm{SO}_{4}$ in different immersion periods of 30,60 and $180 \mathrm{~min}$. Their study aimed to exfoliate and reduce graphene sheets at the 3D-printed electrode surfaces. This has led to an increase in edges and defects. Subsequently, this elevates electroactive site exposure for redox reactions of ruthenium 


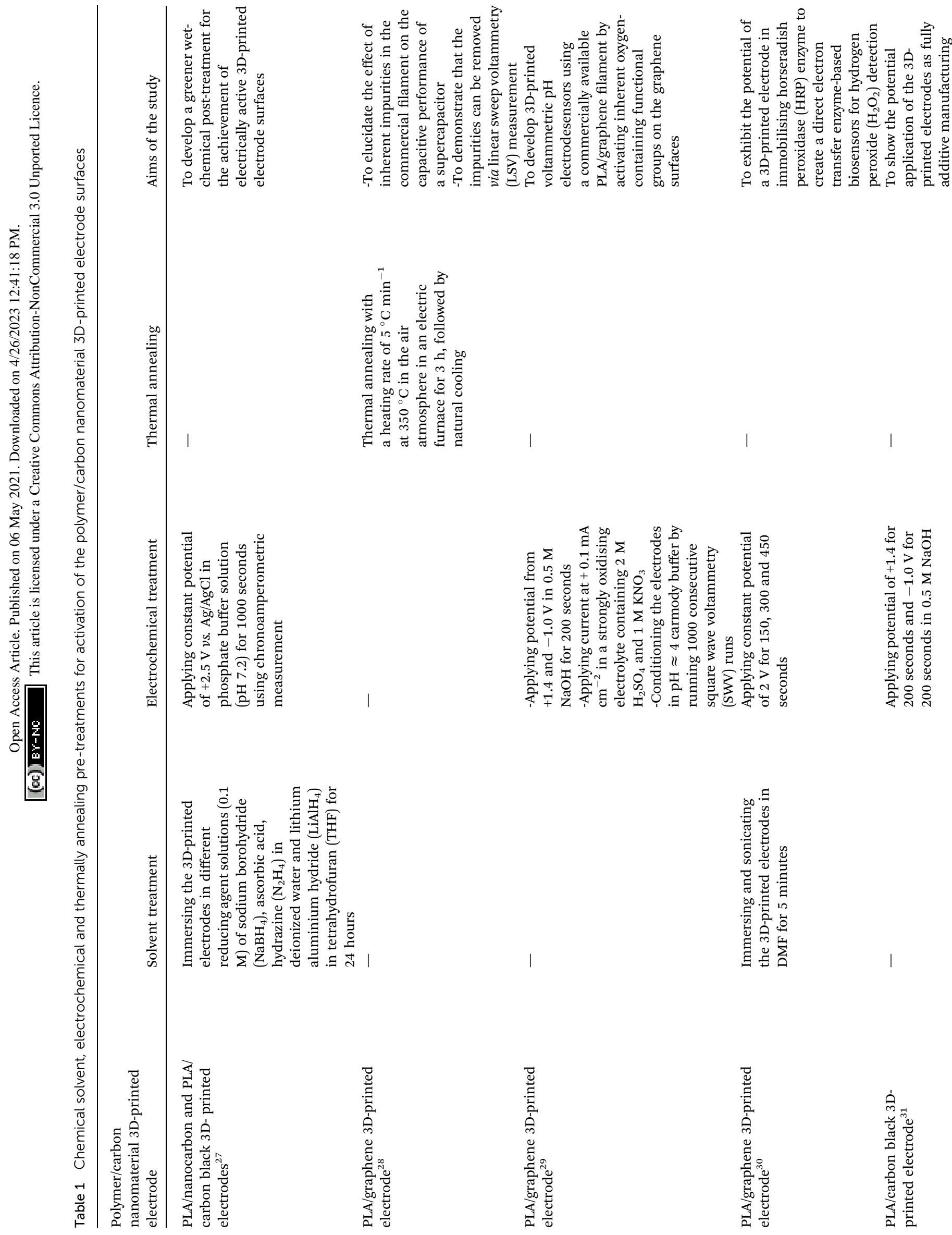




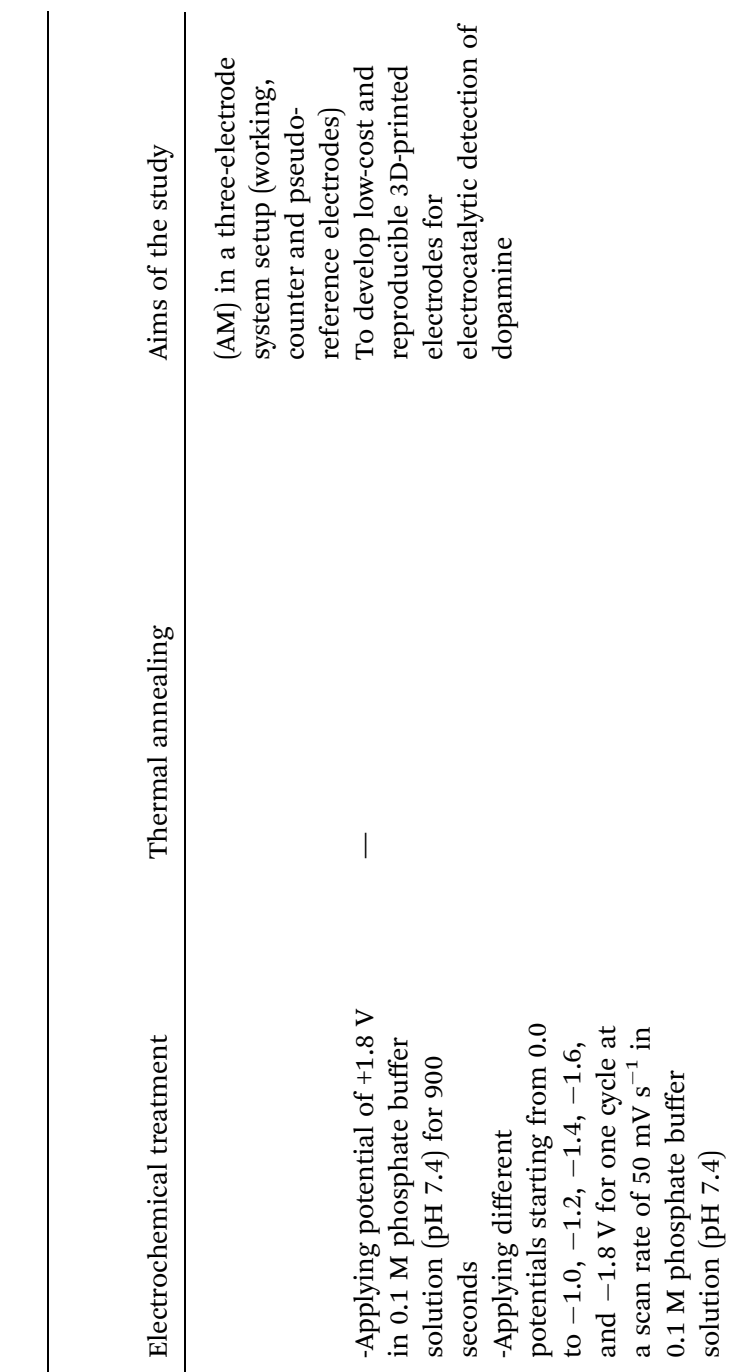

hexamine. Additionally, these made the approaches improve their 3D-printed electrode in sensing dopamine.

Recently, to avoid lengthy electrochemical pre-treatments and harsh chemical treatments, Pumera and co-workers ${ }^{25}$ have reported a new approach by a simple physical method based upon thermal annealing of the PLA/graphene 3D-printed electrodes. Essentially, thermal annealing is a physical process that could control surface roughness in materials where the procedure will modify the surface morphology of material with temperature and time. Commonly, it is performed in a vacuum chamber in an inert ambient such as nitrogen or argon with a specific temperature. ${ }^{26}$ In Pumera and co-workers' approach, thermal annealing for PLA/graphene 3D-printed electrodes was conducted at a temperature over $350{ }^{\circ} \mathrm{C}$ with a heating rate of $5{ }^{\circ} \mathrm{C} \mathrm{min}{ }^{-1}$ at a pressure of $200 \mathrm{~Pa}$ and $\mathrm{N}_{2}$ gas $(6 \mathrm{~N})$ in which the temperature was kept constant for $3 \mathrm{~h}$ during the treatment. Then, the electrodes were electrochemically analysed using CV and EIS, respectively. The data obtained from the thermally annealed electrodes were compared with the 3D-printed electrode, activated with DMF solvent. Interestingly, the electrode showed significant enhancement after the thermal annealing gave a significant enhancement in the terms of electrochemical behaviours in which a smaller $\Delta E_{\mathrm{p}}$ and faster $k_{\mathrm{o}}$ value with a magnitude of $10^{-4} \mathrm{~cm} \mathrm{~s}^{-1}$ compared to the activated 3Dprinted electrode in DMF, which only gave $k_{\mathrm{o}}$ value with a magnitude of $10^{-8} \mathrm{~cm} \mathrm{~s}^{-1}$. From the electrode kinetic data, this study shows that the thermally annealed 3D-printed electrode greatly increased the $k_{\mathrm{o}}$ value by a 9655 -fold in comparison to the treated electrode in DMF solution.

This section only discusses the prominent studies that the research community has reported on how the electrochemist could treat the 3D-printed electrode surfaces to significantly improve the performance of the 3D-printed electrodes, fabricated from 3D printable conductive polymer/carbon nanomaterial filaments. Nevertheless, many works have been published to date as summarised in Table 1.

\section{Polymer/carbon nanomaterial 3D- printed electrodes for electrochemical sensors}

Fabrication of polymer/carbon nanomaterial 3D printed electrodes for electrochemical sensor applications have also been significantly studied in previous years. The developed electrochemical sensors have been studied as electrochemical sensing devices in many analytes of interests, including in detecting metals ions, ${ }^{33,34}$ picric and ascorbic acids, ${ }^{35}$ uric acid, ${ }^{31}$ and mycotoxin compound. ${ }^{36}$ Based on our literature search, at present, as discussed in the previous section before the 3Dprinted carbon nanomaterial electrodes were utilised as electrochemical sensor devices, the electrochemical activities of the polymer/carbon nanomaterial 3D-printed electrodes were electrochemically optimised either with the printing orientations or pre-treating the $3 \mathrm{D}$-printed electrode surfaces with chemical substances. 
Patel et al. ${ }^{37}$ show for the first time the PLA/CB 3D-printed electrode in a cone geometry, printed in horizontal orientation has been utilised in ex vivo experiment over gut tissue of guinea pig to simultaneously monitor the serotonin overflow and muscle contraction as displayed in Fig. 4A and B. Serotonin (5-HT) is one of the neurotransmitter molecules that plays an essential role to modulate the motility of the gastrointestinal tissue. In their work, before they applied the PLA/CB 3D-printed electrodes on the gut tissue samples, the electrodes were tested first on the different concentrations of 5HT in Kreb's buffer solution using chronoamperometric measurements, as shown in Fig. 4C. The fabricated electrode shows that the 3D-printed electrode gave a linear range between 1-10 $\mu \mathrm{M}$. Interestingly, this range of concentration corresponds with the physiological concentrations of the 5-HT present in the gastrointestinal tissue for 15 min without significant electrode fouling as shown in Fig. 4D and offered a limit of the detection as low as $540 \mathrm{nM}$. Overall, their work is the first to show that the PLA/CB 3Dprinted electrode device can conduct dual measurement of signalling, and contractility. This offers significant scope for clinical application, in particular, to monitor bowel function that could be a direct function of therapeutic management of patients with bowel disorders. ${ }^{38}$ The most exciting thing about their work is that the 3D-printed electrode was not undergoing any pre-treatment before the electrochemical measurements.
A different conductive thermoplastic carbon nanomaterial, Katic and co-workers, ${ }^{39}$ have developed PLA/graphene 3Dprinted electrodes, using the FDM method to create chemically modified 3D-printed electrode for the detection of $\mathrm{H}_{2} \mathrm{O}_{2}$. The electrodes have also been activated by using a similar approach based on their previous study. ${ }^{32}$ The authors reported that these activated 3D-printed electrodes have had the same electrochemical behaviour as regularly used electrodes, such as gold and GC electrodes. Furthermore, the PLA/graphene 3Dprinted electrodes have been modified with Prussian blue (PB) by using the chronoamperometric technique through the electrodeposition method and evaluated for the detection of the $\mathrm{H}_{2} \mathrm{O}_{2}$. Then, PB/PLA/graphene modified 3D-printed electrodes have been compared to the unmodified PLA/graphene 3Dprinted electrode for the sensing of $\mathrm{H}_{2} \mathrm{O}_{2}$. The results showed that only PB modified PLA/graphene 3D-printed electrode could detect $\mathrm{H}_{2} \mathrm{O}_{2}$ as there were oxidation and reduction peaks shown in the CV. Meanwhile, there were no peaks shown for the unmodified PLA/graphene 3D-printed electrode. The electrochemical response of the PB modified PLA/graphene 3D-printed electrodes for sensing $\mathrm{H}_{2} \mathrm{O}_{2}$ has been studied using the amperometric technique with a concentration of $\mathrm{H}_{2} \mathrm{O}_{2}$ from 2.0 $\mu \mathrm{M}$ to $112.0 \mu \mathrm{M}$ and LOD obtained for the PB modified electrode was $0.44 \mu \mathrm{M}$.
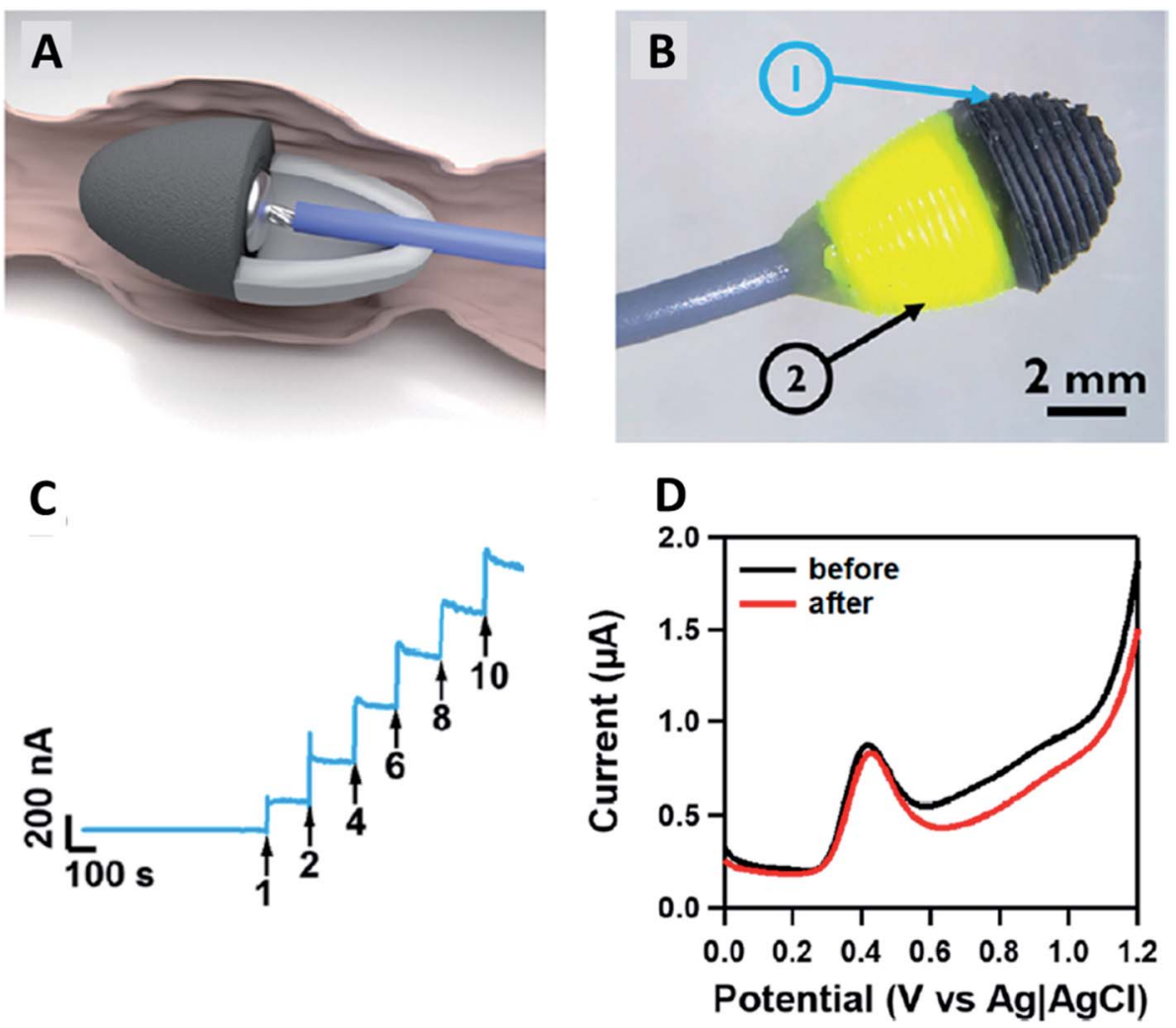

Fig. 4 (A and B) Fabricated a cone PLA/CB 3D-printed electrode that mimics faecal pellets to suit guinea pig's anorectal tissue for ex vivo experiment. (C) Chronoamperogram for an experimental response of the addition 5-HT in a Krebs buffer solution with different concentrations of the 5-HT (1-10 $\mu \mathrm{M})$, held at a constant potential of $+0.6 \mathrm{~V} v \mathrm{~s}$. Ag/AgCl. (D) Differential pulse voltammograms (DPVs) of $5 \mu \mathrm{M} 5-\mathrm{HT}$ in a Krebs buffer solution $(\mathrm{pH}$ 7.4) before and after ex vivo tissue measurement to investigate the electrode's fouling surface. This figure has been reproduced from ref. 37 with permission from AMERICAN CHEMICAL SOCIETY, copyright 2019. 
Meanwhile, Pumera et al. ${ }^{36}$ have printed PLA/graphene 3Dprinted electrode to detect a mycotoxin of zearalenone (ZEA) compound. Like in their previous work, ${ }^{35}$ the authors treated the PLA/graphene 3D-printed electrodes before using them as electrodesensors. The authors have tested the ability of PLA/ graphene 3D-printed electrodes to detect ZEA. The printed electrodes showed a very well-defined anodic peak in CV analysis compared to GC and edge-plane pyrolytic graphite (EPPG) in which the GC and EPPG produced lower signals in the same analysis as illustrated in Fig. 5A and B. This showcased that the PLA/graphene 3D-printed electrodes can detect ZEA. The PLA/ graphene 3D-printed electrodes have shown the capability to detect ZEA at a broad range of concentrations from 10 to $300 \mu \mathrm{M}$ with a linear correlation value of 0.995 , nearly to the ideal value of 1 . The 3D printed electrodes also gave the LOD of $0.340 \mu \mathrm{M}$ and limit of quantification (LOQ) of $1.13 \mu \mathrm{M}$ when compared to the GC electrode, which had an LOD of $0.0683 \mu \mathrm{M}$ and LOQ of $0.228 \mu \mathrm{M}$. This dictates that the PLA/graphene 3D-printed electrodes had a better capability for ZEA detection.

In contrast to other literature discussed in this section, Rocha et al. $^{\mathbf{4 0}}$ utilised PLA/CB filament to fabricate 3D-printed electrode to detect metal ions in biological specimens. Routinely, activation or pre-treatment steps are needed to obtain more conductive sites of a $3 \mathrm{D}$ printed electrode. Thus, the authors have activated the PLA/CB 3D-printed electrode in $0.5 \mathrm{M} \mathrm{NaOH}$. The authors also reported that the surface porosity of the PLA/CB 3D printed electrode increased, through scanning electron microscopy (SEM) analysis after the activation steps, indicating growing CB nanoparticles at the electrode's surface. The activated PLA/CB 3D-printed electrode also had better electrochemical behaviour (higher electroactive surface area and faster electron transfer reactions) than the unactivated PLA/ CB 3D-printed electrode. The sensitivity of activated PLA/CB 3Dprinted electrode towards metals ions (cadmium ion $\left(\mathrm{Cd}^{2+}\right)$ and lead ion, $\left.\left(\mathrm{Pb}^{2+}\right)\right)$ also increased enormously compared to the unactivated PLA/CB 3D-printed electrode. For the metal sensing application, the activated PLA/CB 3D-printed electrodes have been reported to have a wide linear range of $30 \mu \mathrm{g} \mathrm{L}^{-1}$ to $270 \mu \mathrm{g}$ $\mathrm{L}^{-1}$ for both $\mathrm{Cd}^{2+}$ and $\mathrm{Pb}^{2+}$ ions, given the LOD of $2.9 \mu \mathrm{g} \mathrm{\textrm {L } ^ { - 1 }}$ and $2.6 \mu \mathrm{g} \mathrm{L}^{-1}$, and LOQ of $8.9 \mu \mathrm{g} \mathrm{L}^{-1}$ and $7.9 \mu \mathrm{g} \mathrm{L}^{-1}$, respectively. Furthermore, these activated PLA/CB 3D-printed electrodes have been tested in biological samples (urine and saliva). From
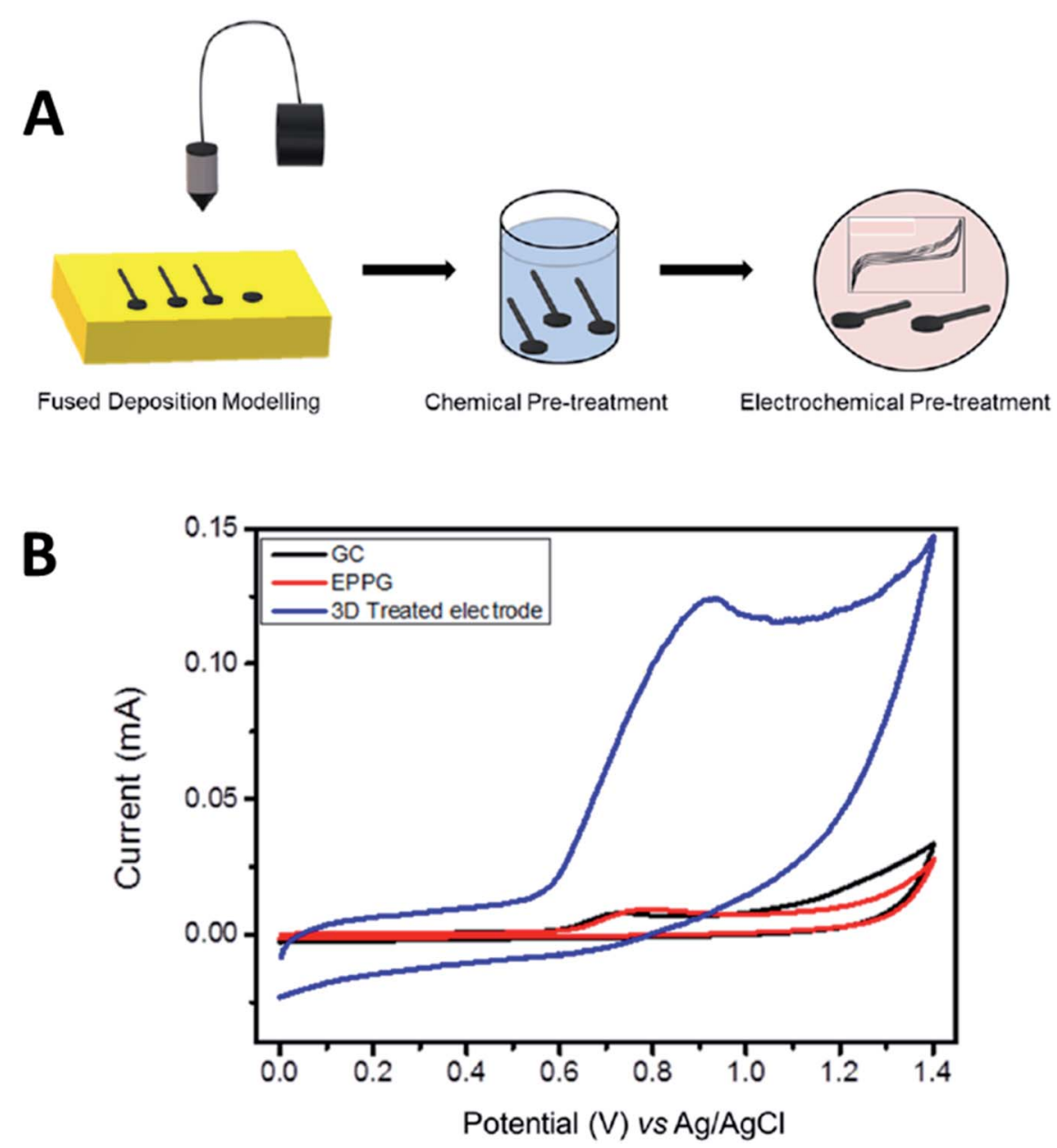

Fig. 5 (A) Pre-activation of the PLA/graphene 3D-printed electrode based upon chemical solvent and electrochemical treatments. (B) CV responses for detecting $100 \mu \mathrm{M}$ zearalenone (ZEA), a mycotoxin compound in a $0.01 \mathrm{M}$ PB solution (pH 7.2) using the treated PLA/graphene 3Dprinted electrode, GC electrode and EPPG electrode at a scan rate of $100 \mathrm{mV} \mathrm{s}^{-1}$. This figure has been reproduced from ref. 36 with permission from ELSEVIER, copyright 2020. 


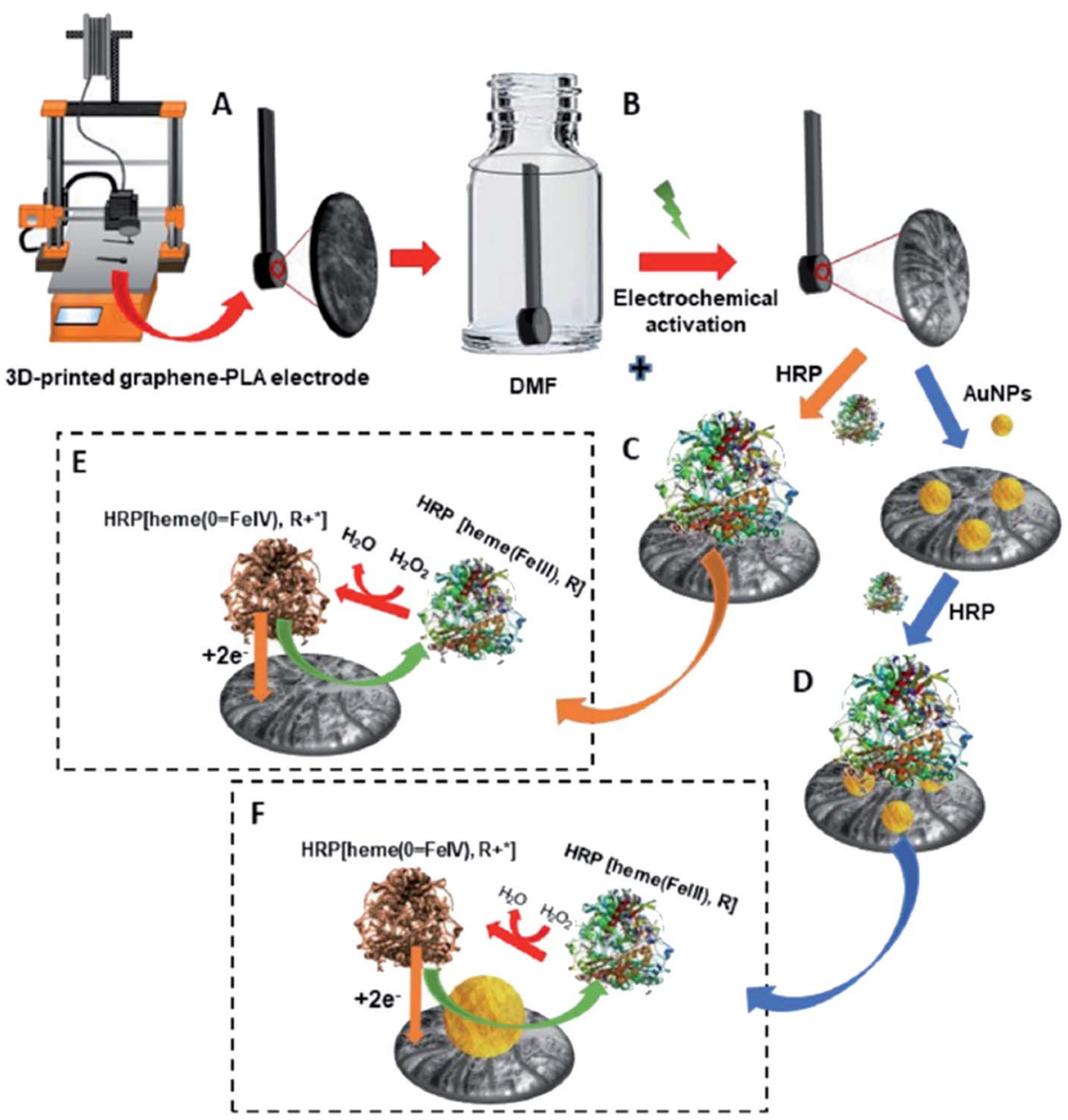

Fig. 6 Schematic diagram for (A) PLA/graphene 3D-printed electrode. (B) Treatment of the 3D-printed electrode in DMF solution for 10 min and also by electrochemical activation. (C) Immobilisation of HRP enzyme onto PLA/graphene 3D-printed electrode by using a physical adsorption method to obtain the HRP modified PLA/graphene 3D-printed electrode. (D) Modification of the PLA/graphene 3D-printed electrode with AuNps and immobilisation of HRP at AuNPs modified PLA/graphene 3D-printed electrode to obtain HRP/AuNPs modified PLA/graphene 3D-printed electrode. ( $\mathrm{E}$ and $\mathrm{F}$ ) Are the proposed mechanisms for detecting $\mathrm{H}_{2} \mathrm{O}_{2}$ at HRP modified PLA/graphene 3D-printed and HRP/AuNPs modified PLA/ graphene 3D-printed electrodes. This figure has been retrieved from ref. 30 with permission from ELSEVIER, copyright 2020.

the result obtained, the 3D-printed electrodes have shown good accuracy with an acceptable recovery value of $93 \%$ to $108 \%$ and $96 \%$ to $112 \%$ for $\mathrm{Cd}^{2+}$ and $\mathrm{Pb}^{2+}$, respectively. Besides, the authors also carried out an interference study and reported that the activated 3D-printed electrodes are also able to detect other metal ions such as copper(II) ion $\left(\mathrm{Cu}^{2+}\right)$ and mercuric ion $\left(\mathrm{Hg}^{2+}\right)$.

\section{Polymer/carbon nanomaterial 3D- printed electrodes for electrochemical biosensors}

Apart from electrochemical sensor applications, currently, there is an increasing trend on how polymers/carbon nanomaterial 3D-printed electrodes could be used to construct electrochemical biosensing electrode substrates. Practically, biomolecules; enzymes, nucleic acids (DNA) and antibodies are immobilised at the electrode substrates as a biosensor probe before using it to sense the specifically targeted analytes. The immobilised biomolecules at the electrode surfaces could be achieved either using physical adsorption, self-assembly monolayer, polymer coating or covalent immobilisation methods. ${ }^{41}$ The targeted analytes could be cancer biomarkers, ${ }^{41}$ viruses ${ }^{42}$ cardiac biomarkers, ${ }^{43,44}$ glucose,${ }^{45}$ hydrogen peroxide $\left(\mathrm{H}_{2} \mathrm{O}_{2}\right),{ }^{46}$ foodborne pathogens ${ }^{47}$ and heavy metal ions. ${ }^{48}$ The common electrode substrates used to construct the immobilised biomolecule probes are GC electrode,$^{49}$ gold electrode, ${ }^{50,51}$ screen-printed carbon electrode (SPCE) $)^{52,53}$ and indium tin oxide (ITO) electrode. ${ }^{45,54}$ To the best of our knowledge, only a few articles have been initiated in reporting the accessibility of the conductive thermoplastic carbon nanomaterial 3D-printed electrodes as electrode platforms for electrochemical biosensing purposes.

A fascinating study has been designed by Pumera et $a l^{30}$ where the PLA/graphene 3D-printed electrodes were used to immobilise horseradish peroxidase (HRP) enzyme to construct enzymatic biosensors based on a direct electron transfer enzyme in sensing $\mathrm{H}_{2} \mathrm{O}_{2}$. Two types of electrodes were then prepared, one with gold nanoparticles (AuNPs) modified PLA/ graphene 3D-printed electrode (AuNPs/PLA/graphene) and one 
without the modification of AuNPs (PLA/graphene). The HRP enzyme was then immobilised at the surface of both 3D graphene/PLA/AuNPs and 3D graphene/PLA based on physical adsorption (by drop-casting method), incubated overnight at $7{ }^{\circ} \mathrm{C}$, producing 3D-printed electrode biosensors as depicted in Fig. 6. The 3D-printed electrode biosensors were then used to detect $\mathrm{H}_{2} \mathrm{O}_{2}$, which involved the mechanism of the HRP enzyme electron transfer reaction. The authors have concluded that the mechanism of electron transfer between the HRP and $\mathrm{H}_{2} \mathrm{O}_{2}$ was based upon direct electron transfer from the HRP enzyme without mediators or binder polymers. It is a fact that the $\mathrm{H}_{2} \mathrm{O}_{2}$ can be detected when it undergoes a reduction process. This will make the HRP contain a redox iron centre to be oxidised from $\mathrm{Fe}(\mathrm{III})$ to $\mathrm{Fe}(\mathrm{IV})$ state. The $\mathrm{Fe}(\mathrm{Iv})$ will then be reduced to its original condition, Fe(III), by applying a negative potential that is almost zero value. The authors also reported that without the HRP enzyme, the PLA/graphene 3D-printed electrodes, with or without AuNPs could not electrocatalyst the $\mathrm{H}_{2} \mathrm{O}_{2}$, resulting in no detection of $\mathrm{H}_{2} \mathrm{O}_{2}$. Furthermore, the AuNPs/HRP modified 3D-printed electrode showed slightly better electrocatalytic performance than $\mathrm{HRP} /$ modified 3D-printed electrode. The chronoamperometric technique was utilised for the detection of $\mathrm{H}_{2} \mathrm{O}_{2}$ in PBS buffer ( $\mathrm{pH}$ 7.2) and human plasma. From the result obtained in the chronoamperometric analyses, HRP modified PLA/graphene 3D-printed electrode had an LOD of $11.1 \mu \mathrm{M}$ and LOQ of $37.0 \mu \mathrm{M}$ with the linearity of 0.994. Meanwhile, AuNPs/ HRP changed the 3D-printed electrode with slightly lower LOD and LOQ $(9.1 \mu \mathrm{M}$ and $30.4 \mu \mathrm{M})$, respectively, with the linearity of 0.996 .

In a different study, Muñoz and colleagues ${ }^{55}$ have also studied the PLA/graphene 3D-printed electrodes for glucose biosensing applications, achieved through the mediation of electron transfer by ferrocene-carboxylic acid (FCA) in developing an amperometric biosensor. Initially, the $3 \mathrm{D}$ printed electrodes have been activated in DMF for 10 minutes. Afterwards, a drop-casting method was carried out on the PLA/ graphene 3D-printed electrodes to fabricate glucose biosensor. The used enzyme probe was glucose oxidase (GOx), immobilised at the surface of the PLA/graphene 3D-printed electrodes based upon physical adsorption. This approach is similar to Pumera and co-workers. ${ }^{30}$ Then the glutaraldehyde solution was dropped on top of the immobilised GOx layer as a crosslinking polymer matrix to make the immobilised GOx enzyme more stable to entrap at the electrode surface. The PLA/graphene 3Dprinted electrode played as a transducer in this glucose biosensor. Additionally, the FCA, which contained a redox iron centre, has been used as a mediator in this glucose biosensor. They proposed that the electrochemical response follows a second-generation glucose biosensor, as illustrated in Fig. 7.

Based on Fig. 7, they suggested that the glucose biosensor detection system follows a second-generation glucose biosensor where the two steps of reactions occurred. In the first step, flavin adenine dinucleotide (FAD) (active centre of the enzyme) acts as an electron mediator for glucose oxidation to gluconolactone, and reduces to flavin adenine dinucleotide $\left(\mathrm{FADH}_{2}\right)$. Thus, the FAD is converted to $\mathrm{FADH}_{2}$, subsequently catalysing glucose oxidation reaction. Then, in the second step, the

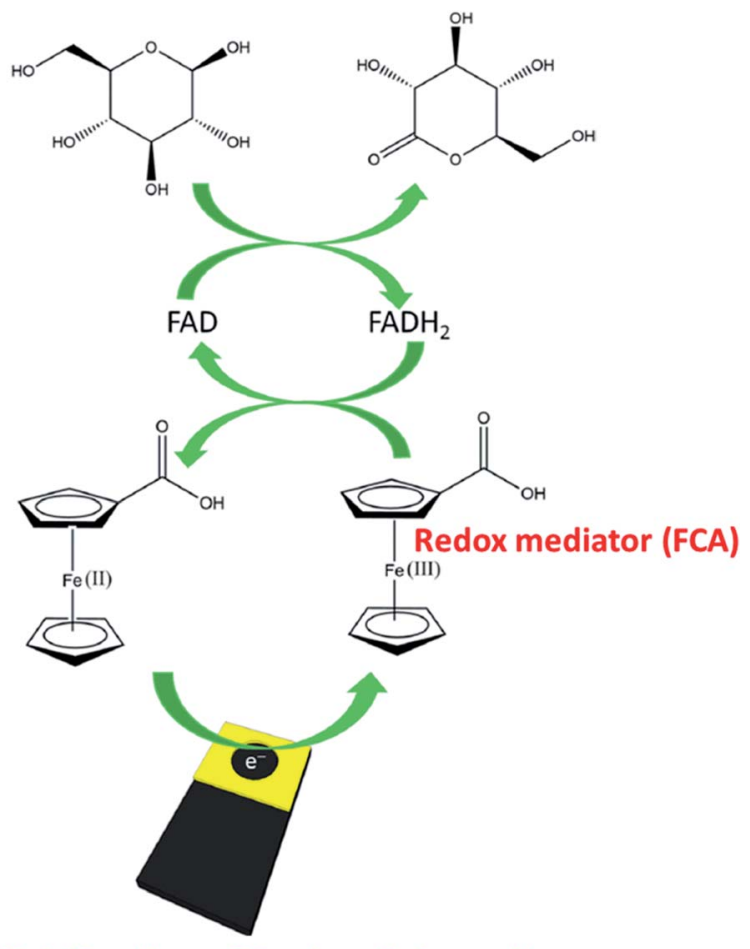

PLA/Graphene 3D-printed electrode

Fig. 7 Proposed detection system for immobilised GOx enzyme at the PLA/graphene 3D-printed electrode for glucose detection, mediated by FCA. This figure has been adapted from ref. 55 with permission from ELSEVIER, copyright 2020.

reduced species of the $\mathrm{FADH}_{2}$ is returned to the FAD species, and the electron involved in this oxidation reaction is transferred to FCA, in which the electrode produced during the oxidation process will reduce $\mathrm{Fe}(\mathrm{III})$ to $\mathrm{Fe}(\mathrm{II})$. The authors have also optimised the parameters in the fabrication of this glucose biosensor, such as $\mathrm{pH}$ value $(\mathrm{pH} 7)$ and the enzyme concentrations ( 6 units per electrode). After the optimisation steps, the fabricated biosensor is tested using the chronoamperometric technique in glucose with a variety concentration from 0 to $6.3 \mathrm{mmol} \mathrm{L}^{-1}$ at a constant potential of $+0.4 \mathrm{~V}$. From the result obtained, the biosensor showed linear behaviour with an LOD of $15 \mu \mathrm{mol} \mathrm{L}{ }^{-1}$ and $R^{2}$ value of 0.998 . The PLA/graphene 3Dprinted biosensor has also been tested in human plasma for glucose detection. The developed 3D-printed electrode biosensor has shown a satisfactory recovery value of 94 to $104 \%$ and was reported stable even after being used in 15 measurements.

Another interesting study of the 3D-printed electrode as an electrochemical biosensor probe was presented by Janegitz et $a l .{ }^{56}$ to detect catechol through the immobilised tyrosinase enzyme at the 3D-printed electrode surface, as displayed in Fig. 8. In their work, PLA/reduced graphene oxide (RGO) 3Dprinted electrodes were fabricated. Before using them as a biosensor probe, the 3D-printed electrodes were activated with solvent treatments. Then the tyrosinase enzyme was immobilised at the electrode surface through the physical absorption method using the drop-casting technique. To obtain stabilised 


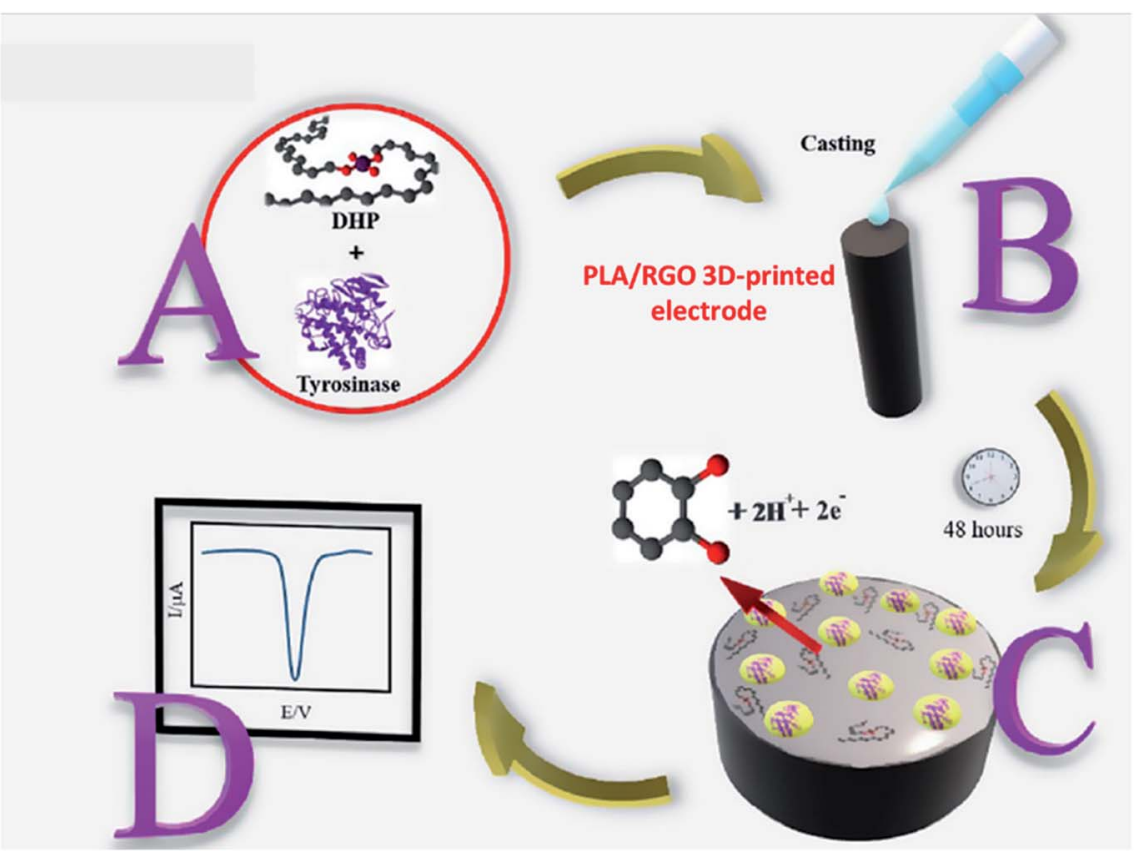

Fig. 8 The schematic diagram for steps to prepare immobilised tyrosinase enzyme, coated with the DHP film to detect catechol. (A) The mixture of tyrosinase enzyme and DHP solution. (B) Drop-casting method of tyrosinase/DHP solution onto PLA/RGO 3D-printed electrode surface. (C) The immobilised tyrosinase/DHP film was obtained. (D) SWV response for detection of catechol after exposure to immobilised tyrosinase probe. This figure has been adapted from ref. 56 with permission from ELSEVIER, copyright 2020.

immobilised enzyme at the electrode surface, before coating the enzyme, the authors prepared the tyrosinase enzyme solution ( 25 units in $10 \mu \mathrm{L}$ ) in hexadecyl phosphate (DHP) solution to maintain the immobilised tyrosinase enzyme at the electrode surface within DHP film as depicted in Fig. 8. The square wave voltammetric (SWV) responses for detection catechol were evaluated to obtain a calibration plot in the range of 30-700 $\mu \mathrm{mol} \mathrm{L}{ }^{-1}$, giving an LOD detection at $0.26 \mu \mathrm{mol} \mathrm{L}^{-1}$ with $R^{2}$ is 0.999 .

Bergamini and colleagues ${ }^{57}$ reported a very different study on the application of the 3D-printed electrodes for the biosensing platform on the development of an immunobiosensor for the detection of Hantavirus Araucaria nucleoprotein (Np). The best thing about their developed method is they employed a covalent immobilisation method to attach IgG2B antibody (HAb) onto the 3D printed PLA/carbon black electrodes using $N$-(3-dimethylaminopropyl)- $N$-ethylcarbodiimidehydrochloride (EDC) and $N$-hydroxysulfosuccinimide sodium salt (NHS) as catalyst reagents. This approach will provide a stable and robust immobilisation of biomolecules at the electrode surface compared to the physical adsorption method. After preparing the immunobiosensor probes, the electrodes were characterised using $\mathrm{CV}$ and EIS in a $\mathrm{K}_{3}\left[\mathrm{Fe}(\mathrm{CN})_{6}\right]$ redox probe solution, as illustrated in Fig. 9. The detection system was analysed by comparing the values of $R_{\mathrm{ct}}$ or CV peak currents before and after sensing the immunobiosensor probes to $\mathrm{Np}$ virus with a concentration range between $30-240 \mu \mathrm{g} \mathrm{mL}^{-1}$, in which the calibration plot gave an LOD value of $22 \mu \mathrm{g} \mathrm{mL}$. Interestingly, the developed immunobiosensor was able to detect $\mathrm{Np}$ virus $0.120 \mathrm{mg} \mathrm{mL}^{-1}$ in spiked human serum samples $(100 \times$ diluted).

\section{Future outlook}

We have discussed polymer/carbon nanomaterial 3D-printed electrodes for electrochemical sensors and electrochemical biosensors based on recent and past studies using the FDM 3D printing method. These 3D printed carbon nanomaterials can be fabricated easily, inexpensive, and straightforwardly to be incorporated with other chemicals for broad electroanalytical applications. Additionally, many published studies have shown that after the electrode treatments, these polymer/carbon nanomaterial 3D-printed electrodes have revealed promising properties such as high anisotropic conductivity, more electroactive sites produced, low resistivity, and high sensitivity in electrochemical sensors and biosensors development. As discussed earlier, the activation steps, whether chemically, electrochemically or thermally, could be employed to increase the electrochemical performance of the 3D-printed electrodes. Thus increasing electrode roughness, and anisotropic conductivity of the treated electrode, resulting in a significant increase in the sensitivity of the 3D printed electrodes. The 3D-printed carbon nanomaterial electrodes are commonly activated in aprotic solvents such as DMF from our literature survey. However, the DMF is a toxic and not eco-friendly chemical. To date, the utilisation of $0.5 \mathrm{M}^{, 6} 1 \mathrm{M}^{24}$ or $3 \mathrm{M} \mathrm{NaOH}^{58}$ solution as a pretreatment 3D-printed electrode can also give a similar advantage as DMF. However, there are still some potential approaches that could be attempted to improve the electrochemical performance of the 3D printed electrodes in the future. One of the methods is by electrochemically treating the 3D-printed carbon nanomaterial electrode in acetonitrile (ACN) with $0.1 \mathrm{M}$ tetrabutylammonium tetrafluoroborate (TBATFB) using 


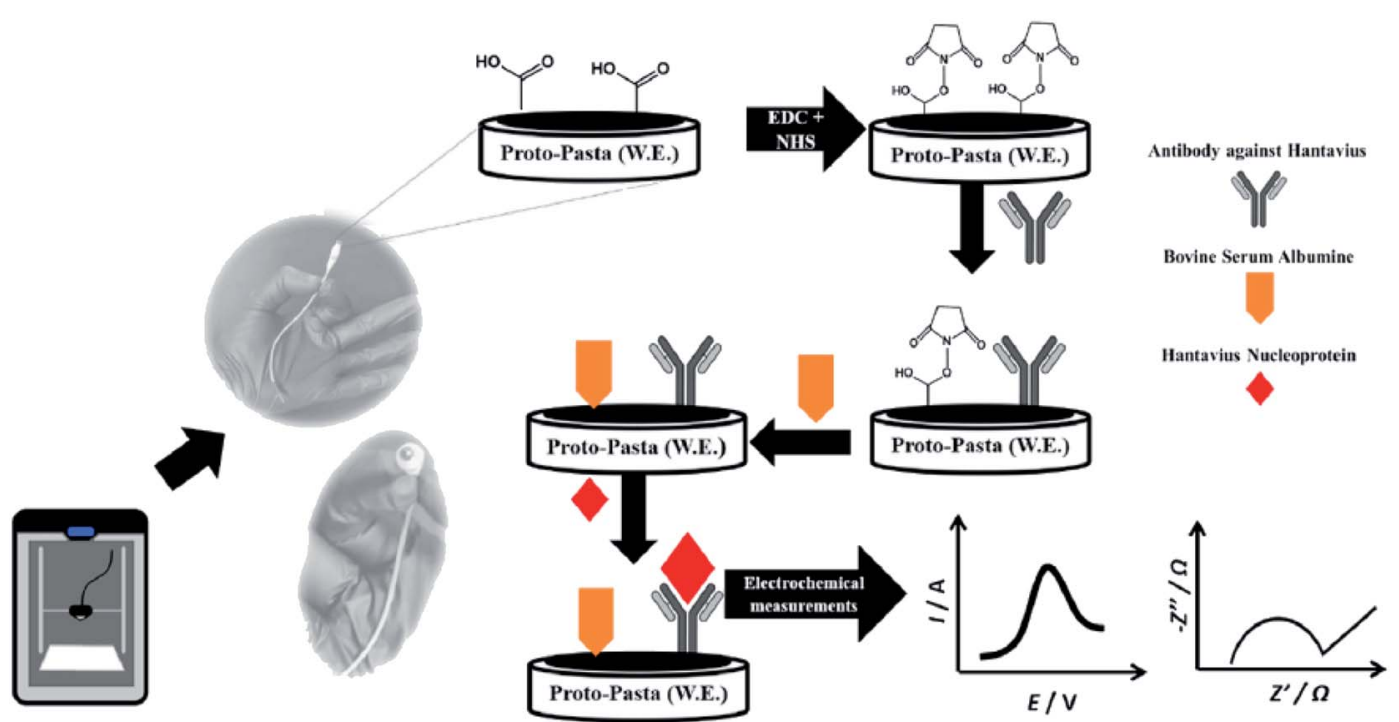

Fig. 9 Steps for creating immunobiosensor for covalent immobilisation of IgG2B antibody (HAb) onto PLA/carbon black 3D-printed electrode surface to detect $\mathrm{Np}$ virus in the human plasma sample. This figure has been adapted from ref. 57 with permission from ELSEVIER, copyright 2021.

$\mathrm{CV}$, cycled the potential between $0-2.0 \mathrm{~V} .{ }^{59}$ This will make the electrode surface rougher, thus, providing more electroactive sites available for redox reactions. In contrast, an enzyme solution could also be used to activate the 3D-printed carbon nanomaterial electrodes. ${ }^{60}$ However, using an enzyme will increase the experiment's cost as the enzyme molecule is very expensive and unstable.

The commonly used conductive thermoplastic carbon nanomaterial filaments are graphene and $\mathrm{CB}$, where both of these filaments are commercially available. However, it would be advantageous if the conductive thermoplastic filaments are made in house by incorporating metal hydroxide, or metal oxide materials to produce conductive thermoplastic nanocomposite filaments. For metal hydroxide, it has been reported that the addition of nickel(II) hydroxide $\left(\mathrm{NiOH}_{2}\right)$ microparticles within a PLA/graphene matrix can produce a non-enzymatic 3Dprinted electrode for creating a glucose sensor, in which $\mathrm{NiOH}_{2}$ can act as an electrocatalyst for glucose. ${ }^{61-63}$ By contrast, ought to be interesting if conductive thermoplastic nanocomposite filaments are developed to be utilised in fabricating 3D-printed electrodes for photoelectrochemical sensors, ${ }^{64,65}$ or biosensors ${ }^{66,67}$ without modification of the electrode surfaces. This can be achieved by integrating tungsten trioxide $\left(\mathrm{WO}_{3}\right),{ }^{68}$ or titanium dioxide $\left(\mathrm{TiO}_{2}\right)^{69}$ particles within polymer/carbon nanomaterial matrixes. This approach would be a very novel idea for developing photoelectrochemical sensors, or biosensors through 3D-printed electrodesensors.

The 3D-printed carbon nanomaterial electrodes' surface can also be modified easily through electrodeposition and chemical deposition methods. These approaches are highly recommended, mainly via the electrodeposition method as through the electrodeposition, the metal and metal oxide nanoparticle films such as electrodeposited gold $(\mathrm{Au})$, platinum $(\mathrm{Pt})$, silver $(\mathrm{Ag})$, palladium $(\mathrm{Pd})$, copper $(\mathrm{Cu})$ and zinc oxide $(\mathrm{ZnO})$ nanoparticles could be obtained, and the electrodeposited metal and metal oxide nanoparticle films could be employed broadly to improve the electrochemical performances of the sensor, and biosensor electrode devices. In a different application, the 3Dprinted electrodes can be made as pseudo-reference and counter electrodes ${ }^{31,58}$ or only as a pseudo-reference electrode ${ }^{70}$ for a three-electrode system set up. Attractively, in the case of the pseudo-reference electrode, it can be generated through electrodeposited, or coated $\mathrm{Ag}$ at the 3D-printed electrode surfaces. To date, it has been shown that the developed pseudoreference electrodes based on 3D-printed electrodes exhibit a similar performance to a commercial $\mathrm{Ag} / \mathrm{AgCl}$ reference electrode. ${ }^{31,70}$ On the contrary, the 3D-printed electrodes can also be utilised as an auxiliary electrode. Thus, this will replace the use of a conventional Pt electrode, and consequently, reducing the analysis cost. To the best of our knowledge, both types of electrodes were fabricated from conductive PLA/graphene filament, ${ }^{58,70}$ or PLA/CB filament. ${ }^{31}$ Hence, it would be of interest if a variety of thermoplastic carbon nanomaterials such as CNTs, or carbon fibers is used to generate the pseudo-reference and counter electrodes. Then, their electrochemical performance can be evaluated and can also be compared to the previous studies. ${ }^{31,58,70}$

From the discussion, the current progress of the applications of the conductive polymer/carbon nanomaterial 3D-printed electrodes, produced from the FDM 3D printing method has a big potential to be employed as electrode substrates to immobilise biomolecules (enzymes and antibodies) in developing electrode biosensing devices via physical adsorption, entrapment with a polymer matrix or solid-phase synthesis with the presence of the catalyst reagents; EDC and NHS. Most of the published works so far only reported as proof-of-concept on the potentials of the 3D-printed electrodes for electrochemical biosensors. Therefore, in the future, some novel concepts, designs and approaches could be developed by the research community to attain robust immobilised biomolecule films at the electrode surface, high selectivity, and high sensitivity of the 3D printed electrodes for electrochemical biosensing purposes. 
For instance, the electrodeposited AuNPs at the 3D-printed carbon nanomaterial electrode could be utilised as a substrate in anchoring various thiol linkers with different lengths and organic functional groups as the specific functional group could be used to covalently bind the enzyme, single-stranded DNA (ssDNA), or antibody molecules. This can be achieved by utilising a self-assembly monolayer method. The 3D-printed carbon nanomaterial electrodes could also be used as electrode substrates for electrografting of primary amine linkers. These linkers play an essential role in obtaining stable monolayer electrografted primary amine linkers ${ }^{59,71}$ that could be used to covalently attach redox probes, enzyme molecules or ssDNA molecules at the electrode surfaces. These modifications are very useful, especially for biosensors applications. The modification of the electrode surfaces is urgently needed for the improvement of the 3D-printed electrode to improve the stability, and selectivity of the biosensor probes in the detection process. The modified 3D-printed electrode could then be applied for the development of biosensors, biofuel cells, and electrocatalysts.

On the other hand, the electrodeposited $\mathrm{Au}, \mathrm{Pt}, \mathrm{Pd}, \mathrm{Ag}$, and $\mathrm{Cu}$ nanoparticles at 3D-printed carbon nanomaterial electrodes could be utilised as electrocatalyst platforms to study oxygen reduction reaction (ORR), oxygen evolution reaction, hydrogen evolution reaction and carbon dioxide reduction reaction. This gives a significant potential to develop electrochemical sensors to detect dissolved $\mathrm{O}_{2}$ and $\mathrm{CO}_{2}$ molecules in an aqueous solution. In conclusion, thermoplastic $3 \mathrm{D}$ printable conductive carbon nanomaterial electrodes have a promising future in electrochemistry and analytical chemistry research. Considering the current on-demand applications of the conductive 3Dprinted electrodes in developing electrochemical sensors and biosensors, further studies ought to be carried out with different thermoplastic carbon nanomaterial filaments used in the FDM 3D printing process (e.g., carbon fibers ${ }^{72}$ ). More optimization processes over individually adjustable FDM 3D printing parameters such as infill percentage, printing speed and temperature, and surface inclination angle can be explored to obtain the best 3D-printed electrode products in the selected electrochemistry applications by exploring their electrochemical performance.

\section{Conflicts of interest}

There are no conflicts to declare.

\section{Acknowledgements}

The authors gratefully acknowledge the financial support from the Ministry of Higher Education Malaysia (MOHE) under the Fundamental Research Grant Scheme (FRGS) grant (230.PKIMIA.6711919).

\section{References}

1 H. H. Hamzah, S. A. Shafiee, A. Abdalla and B. A. Patel, Electrochem. Commun., 2018, 96, 27-31.
2 M. Elbadawi, J. J. Ong, T. D. Pollard, S. Gaisford and A. W. Basit, Adv. Funct. Mater., 2020, 31, 1-26.

3 P. Chang, H. Mei, S. Zhou, K. G. Dassios and L. Cheng, J. Mater. Chem. A, 2019, 7, 4230-4258.

4 Q. Wei, H. Li, G. Liu, Y. He, Y. Wang, Y. E. Tan, D. Wang, X. Peng, G. Yang and N. Tsubaki, Nat. Commun., 2020, 11, 1-8.

5 L. Wang and M. Pumera, TrAC, Trends Anal. Chem., 2021, 135, 116151.

6 A. Ambrosi and M. Pumera, Chem. Soc. Rev., 2016, 45, 27402755.

7 N. Shahrubudin, T. C. Lee and R. Ramlan, Procedia Manufacturing, 2019, 35, 1286-1296.

8 J. Muñoz and M. Pumera, TrAC, Trends Anal. Chem., 2020, 128, 115933.

9 P. K. Penumakala, J. Santo and A. Thomas, Composites, Part B, 2020, 201, 108336.

10 J. Sánchez del Río, C. Pascual-González, V. Martínez, J. L. Jiménez and C. González, Sens. Actuators, A, 2021, 317, 112422.

11 X. Kong, P. Gai, L. Ge and F. Li, ACS Sustainable Chem. Eng., 2020, 8, 12437-12442.

12 L. Ge, Q. Hong, H. Li, C. Liu and F. Li, Adv. Funct. Mater., 2019, 29, 1904000.

13 S. F. A. Acquah, B. E. Leonhardt, M. S. Nowotarski, J. M. Magi, K. A. Chambliss, T. E. S. Venzel, S. D. Delekar and L. A. Al-Hariri, in Carbon Nanotubes - Current Progress of their Polymer Composites, 2016, pp. 227-250.

14 N. P. Kim, Polymers, 2020, 12, 1-12.

15 R. K. Gautam and A. Verma, in Microbial Electrochemical Technology, 2019, pp. 451-483.

16 C. W. Foster, H. M. Elbardisy, M. P. Down, E. M. Keefe, G. C. Smith and C. E. Banks, Chem. Eng. J., 2020, 381, 122343.

17 H. H. Bin Hamzah, O. Keattch, D. Covill and B. A. Patel, Sci. Rep., 2018, 8, 9135.

18 W. Ye, W. Wu, X. Hu, G. Lin, J. Guo, H. Qu and J. Zhao, Compos. Sci. Technol., 2019, 182, 107671.

19 K. Gnanasekaran, T. Heijmans, S. van Bennekom, H. Woldhuis, S. Wijnia, G. de With and H. Friedrich, Applied Materials Today, 2017, 9, 21-28.

20 A. Abdalla, H. H. Hamzah, O. Keattch, D. Covill and B. A. Patel, Electrochim. Acta, 2020, 354, 136618.

21 M. P. Browne, F. Novotný, Z. Sofer and M. Pumera, ACS Appl. Mater. Interfaces, 2018, 10, 40294-403301.

22 R. Gusmão, M. P. Browne, Z. Sofer and M. Pumera, Electrochem. Commun., 2019, 102, 83-88.

23 E. Vaněčková, M. Bouša, Š. Nováková Lachmanová, J. Rathouský, M. Gál, T. Sebechlebská and V. Kolivoška, J. Electroanal. Chem., 2020, 857, 113745.

24 C. Kalinke, N. V. Neumsteir, G. D. O. Aparecido, T. V. D. B. Ferraz, P. L. Dos Santos, B. C. Janegitz and J. A. Bonacin, Analyst, 2020, 145, 1207-1218.

25 F. Novotný, V. Urbanová, J. Plutnar and M. Pumera, ACS Appl. Mater. Interfaces, 2019, 11, 35371-35375.

26 G. M. Alonzo-Medina, A. González-González, J. L. Sacedón and A. I. Oliva, IOP Conf. Ser.: Mater. Sci. Eng., 2013, 45, 012013. 
27 E. Redondo, J. Muñoz and M. Pumera, Carbon, 2021, 175, 413-419.

28 K. Ghosh, S. Ng, C. Iffelsberger and M. Pumera, Chem.-Eur. J., 2020, 26, 1-6.

29 F. M. Rabboh and G. D. O'Neil, Anal. Chem., 2020, 92, 1499915006.

30 A. M. López Marzo, C. C. Mayorga-Martinez and M. Pumera, Biosens. Bioelectron., 2020, 151, 111980.

31 E. M. Richter, D. P. Rocha, R. M. Cardoso, E. M. Keefe, C. W. Foster, R. A. A. Munoz and C. E. Banks, Anal. Chem., 2019, 91, 12844-12851.

32 P. L. dos Santos, V. Katic, H. C. Loureiro, M. F. dos Santos, D. P. dos Santos, A. L. B. Formiga and J. A. Bonacin, Sens. Actuators, B, 2019, 281, 837-848.

33 K. C. Honeychurch, Z. Rymansaib and P. Iravani, Sens. Actuators, B, 2018, 267, 476-482.

34 J. G. Walters, S. Ahmed, I. M. Terrero Rodríguez and G. D. O'Neil, Electroanalysis, 2020, 32, 1-9.

35 C. L. Manzanares Palenzuela, F. Novotný, P. Krupička, Z. Sofer and M. Pumera, Anal. Chem., 2018, 90, 5753-5757.

36 M. Zafir Mohamad Nasir, F. Novotný, O. Alduhaish and M. Pumera, Electrochem. Commun., 2020, 115, 106735.

37 H. H. Hamzah, O. Keattch, M. S. Yeoman, D. Covill and B. A. Patel, Anal. Chem., 2019, 91, 12014-12020.

38 B. Patel, H. Hamzah, D. Covill and M. Yeoman, Gut, 2021, 70, A202.

39 V. Katic, P. L. Dos Santos, M. F. Dos Santos, B. M. Pires, H. C. Loureiro, A. P. Lima, J. C. M. Queiroz, R. Landers, R. A. A. Muñoz and J. A. Bonacin, ACS Appl. Mater. Interfaces, 2019, 11, 35068-35078.

40 D. P. Rocha, A. L. Squissato, S. M. da Silva, E. M. Richter and R. A. A. Munoz, Electrochim. Acta, 2020, 335, 135688.

41 K. Malecka, E. Mikuła and E. E. Ferapontova, Sensors, 2021, 21, 736.

42 M. R. de Eguilaz, L. R. Cumba and R. J. Forster, Electrochem. Commun., 2020, 116, 106762.

43 A. Baradoke, R. Hein, X. Li and J. J. Davis, Anal. Chem., 2020, 92, 3508-3511.

44 M. Pedrero, S. Campuzano and J. M. Pingarrón, Electroanalysis, 2014, 26, 1-22.

45 N. S. Ridhuan, K. Abdul Razak and Z. Lockman, Sci. Rep., 2018, 8, 13722.

46 N. Zou, X. Wei, Z. Zong, X. Li, Z. Wang and X. Wang, J. Chem. Sci., 2019, 131, 1-8.

47 Z. Zhang, J. Zhou and X. Du, Micromachines, 2019, 10, 222.

48 M. R. Saidur, A. R. A. Aziz and W. J. Basirun, Biosens. Bioelectron., 2017, 90, 125-139.

49 Q. Yan, N. Zhi, L. Yang, G. Xu, Q. Feng, Q. Zhang and S. Sun, Sci. Rep., 2020, 10, 10607.

50 S. A. Goodchild, R. Gao, D. P. Shenton, A. J. S. McIntosh, T. Brown and P. N. Bartlett, Front. Chem., 2020, 8, 381.

51 N. A. Mansor, Z. M. Zain, H. H. Hamzah, M. S. A. Noorden, S. S. Jaapar, V. Beni and Z. H. Ibupoto, Open J. Appl. Biosens., 2014, 03, 9-17.
52 N. Mohamad Nor, K. Abdul Razak and Z. Lockman, Electrochim. Acta, 2017, 248, 160-168.

53 W. Białobrzeska, D. Firganek, M. Czerkies, T. Lipniacki, M. Skwarecka, K. Dziąbowska, Z. Cebula, N. Malinowska, D. Bigus, E. Bięga, K. Pyrć, K. Pala, S. Żołędowska and D. Nidzworski, Biosensors, 2020, 10, 1-13.

54 N. S. Ridhuan, N. Mohamad Nor, K. Abdul Razak, Z. Lockman and N. D. Zakaria, J. Solid State Electrochem., 2021, 25, 1065-1072.

55 R. M. Cardoso, P. R. L. Silva, A. P. Lima, D. P. Rocha, T. C. Oliveira, T. M. do Prado, E. L. Fava, O. FatibelloFilho, E. M. Richter and R. A. A. Muñoz, Sens. Actuators, B, 2020, 307, 127621.

56 V. A. O. P. Silva, W. S. Fernandes-Junior, D. P. Rocha, J. S. Stefano, R. A. A. Munoz, J. A. Bonacin and B. C. Janegitz, Biosens. Bioelectron., 2020, 170, 112684.

57 G. Martins, J. L. Gogola, L. H. Budni, B. C. Janegitz, L. H. Marcolino-Junior and M. F. Bergamini, Anal. Chim. Acta, 2021, 1147, 30-37.

58 C. Kalinke, N. V. Neumsteir, P. Roberto de Oliveira, B. C. Janegitz and J. A. Bonacin, Anal. Chim. Acta, 2021, 1142, 135-142.

59 H. H. Hamzah, N. N. Ahmad Kamal, M. Meneghello, S. A. Shafiee, T. Sönmez, M. N. A. Mohamad Taib, S. H. Mohd Samsuri and M. F. Meor Zulkifli, J. Electrochem. Soc., 2020, 167, 166508.

60 C. L. Manzanares-Palenzuela, S. Hermanova, Z. Sofer and M. Pumera, Nanoscale, 2019, 11, 12124-12131.

61 R. G. Rocha, R. M. Cardoso, P. J. Zambiazi, S. V. F. Castro, T. V. B. Ferraz, G. d. O. Aparecido, J. A. Bonacin, R. A. A. Munoz and E. M. Richter, Anal. Chim. Acta, 2020, 1132, 1-9.

62 S. A. Shafiee, S. C. Perry, H. H. Hamzah, M. M. Mahat, F. A. Al-lolage and M. Z. Ramli, Electrochem. Commun., 2020, 120, 106828.

63 C. Y. Ko, J. H. Huang, S. Raina and W. P. Kang, Analyst, 2013, 138, 3201-3208.

64 B. Li, Y. Chen, A. Peng, X. Chen and X. Chen, J. Colloid Interface Sci., 2019, 537, 528-535.

65 K. Syrek, M. Skolarczyk, M. Zych, M. Sołtys-Mróz and G. D. Sulka, Sensors, 2019, 19, 4981.

66 J. Bai and B. Zhou, Chem. Rev., 2014, 114, 10131-10176.

67 X. Liu, D. Fan, S. Duan, C. Bao, H. Wang, X. Wang, X. Sun and Q. Wei, Anal. Methods, 2019, 11, 3890-3897.

68 M. L. M. Shaath, M. N. M. Ansar, A. Atiqah and A. Hamdan, Int. J. Eng. Adv. Technol., 2019, 9, 2511-2513.

69 S. Nájera, M. Miche, K. Hwan J and N. Soo Kim, J. Mater. Sci. Eng., 2018, 7, 1-8.

70 N. Rohaizad, C. C. Mayorga-Martinez, F. Novotný, R. D. Webster and M. Pumera, Electrochem. Commun., 2019, 103, 104-108.

71 H. H. Hamzah, W. C. Chein, S. S. F. Rahiman and S. A. Shafiee, J. Electrochem. Soc., 2019, 166, H877-H887.

72 Q. Cao, M. Shin, N. V. Lavrik and B. J. Venton, Nano Lett., 2020, 20, 6831-6836. 